\title{
New technological and technical solutions in dietary pear compote production
}

\author{
Magomed Akhmetov ${ }^{1,2,3,{ }^{*}}$, Amiiat Demirova ${ }^{1,2,3}$, Vladimir Piniaskin ${ }^{1}$, and R.A. Rakhmanova ${ }^{3}$ \\ ${ }^{1}$ FSBEO HE Dagestan State Technical University, Makhachkala, Russia \\ ${ }^{2}$ Federal Agrarian Scientific Center of the Republic of Dagestan, Makhachkala, Russia \\ ${ }^{3}$ SEI HPE Dagestan State University of National Economy, Makhachkala, Russia
}

\begin{abstract}
Perfection of technological processes, both in preliminary preparation of raw materials and during the final mandatory step of pasteurization, plays a key role in ensuring the quality of finished products, which is important in the production of canned dietary products. The aim of the research was to develop a more efficient way of blanching raw materials with its hardware and soft pasteurization modes, which will allow the production of high quality and competitive compotes for functional nutrition. We have developed and proposed a method of pulse-steam blanching of raw materials directly in glass jars with saturated water vapor, instead of the traditional method using hot water. The essence of the method is as follows. Fruits stacked in jars are pulse heated for 100-160 seconds (depending on the volume of the container) with saturated water vapor with temperature of $105-110^{\circ} \mathrm{C}$, and then fed into jars with cycles of 10 and 10 seconds respectively. The use of pulsed supply of saturated water vapor contributes to achieving more even heating of the fruit, which are characterized by a relatively large internal thermal resistance, causing overheating of the surface layers, and also provides an increase in the temperature of the product, which allows to pour into the jars syrup at relatively high temperature $\left(97-98^{\circ} \mathrm{C}\right)$, while the traditional technology accounts for the temperature of only $80-85^{\circ} \mathrm{C}$. Implementation of this method ensures the temperature level of the product entering the pasteurization stage being $78-80^{\circ} \mathrm{C}$, as opposed to the traditional method, where the temperature of the product is $45-48{ }^{\circ} \mathrm{C}$. After that, the jars will be filled with syrup with a temperature of $97-98^{\circ} \mathrm{C}$, sealed and sent for pasteurization on accelerated modes. To implement the new method of blanching, the design of the device for pulse-steam blanching of fruits in glass jars has been developed. New thermal sterilization regimes have been developed, taking into account the increased temperature of the product after sealing and improved technology for the production of pear compote. The results of physical and chemical testing confirm the high quality of the finished product.
\end{abstract}

\section{Introduction}

Product quality is an important aspect in the implementation of any technological solution for food production $[1,2,3,4]$, especially for dietary nutrition $[5$, $6,7,8,9,10]$. An important role in ensuring the quality of finished products when producing canned foods for dietary nutrition is played by technological features, both of the preliminary preparation of raw materials and the final mandatory stage in the production of canned foods, pasteurization.

The aim of these studies is to develop a more efficient method of blanching raw materials using pulsesteam processing of fruits directly in glass jars with its hardware and soft pasteurization modes, which will allow the production of high quality and competitive compotes.

In the technology of production of canned compotes, one of the most important stages of fruit preparation is blanching, aimed to stop biochemical processes in the fruit, suppress the vitality of microorganisms, as well as increase the permeability of protoplasm cells and remove air from tissues [11].

At the same time, being a necessary technological operation, the blanching process also plays an important role in improving the quality of the finished product.

In the case of the technology of production of canned pear compote, the procedure of blanching removes air from intercellular passages, causing compaction of tissue, which in turn leads to an increase in its elasticity.

It is also important to take into account the peculiarity that the removal of air during blanching helps in reducing the loss of biologically active components of raw materials.

We should also note that the air contained in plant cells, when getting into the finished products during thermal sterilization, along with the deterioration of the quality of the product, causes at the same time a significant increase in pressure in glass jars during the sterilization process.

In addition to the positive aspects noted, it is also known that the blanching of fruits in hot water, which is

* Corresponding author: akhmag49@mail.ru 

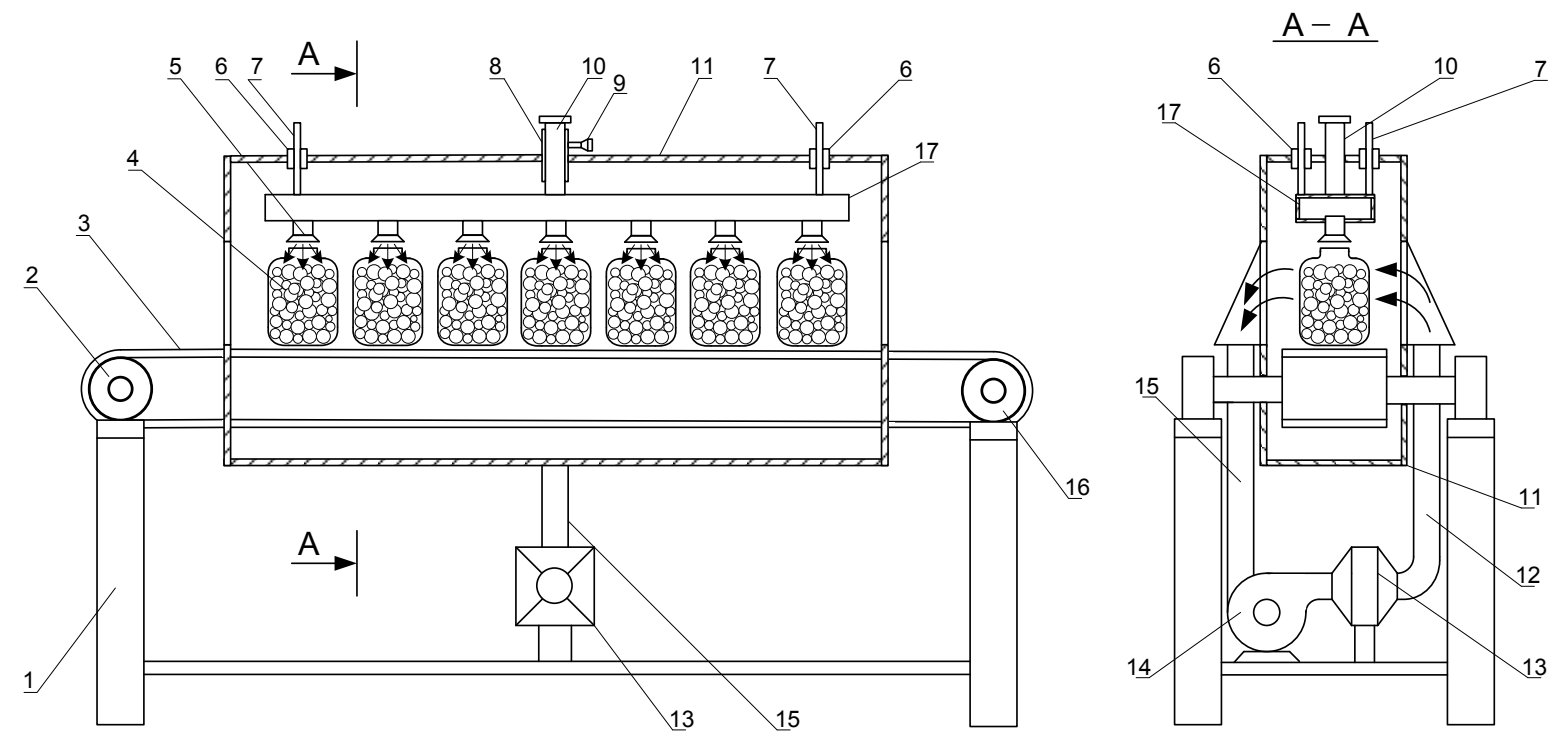

Fig. 1. A device for pulse-steam blanching in jars.

widely practiced at present, results in the loss of more than $20 \%$ of vitamins and other nutrients contained in the raw materials.

\section{Research materials and methods}

The objects of this study are dietary pear compote and the technology of its production, with special attention paid to the process of pre-heating processing of fruitsblanching and pasteurization regimes.

Traditionally, the process of blanching is carried out after cutting and cleaning the fruit in various ways and in devices of different design [13]. Experimental research on pulse-steam blanching of fruits and heating of compote was carried out on experimental installations that allow to model the studied processes in laboratory conditions. An important parameter characterizing both the blanching process and pasteurization is the product temperature, which was measured with $\mathrm{Cr}-\mathrm{Ni}$ and $\mathrm{Cu}-\mathrm{Ni}$ thermocouple attached to a KSP-4 self-recording potentiometer. The development of the pasteurization regime was carried out on the basis of warming schedules, taking into account the value of the expiration rate [12] of microorganisms, providing industrial sterility of the finished product.

\section{Results}

We have developed and proposed a new way of pulsesteam blanching of raw materials directly in glass jars, instead of traditional blanching using hot water.

The method is implemented in the following way: fruits after cutting and cleaning get deposited in glass jars and are subjected to pulse heating for 100-160 seconds (depending on the volume of containers) with saturated water vapor at temperature of $105-110{ }^{\circ} \mathrm{C}$ fed in jars with cycles of 10 and 10 seconds respectively.

The use of pulsed supply of saturated water vapor contributes to more even heating of the fruit that, due to their structure, are characterized by relatively high internal thermal resistance, causing overheating of surface layers. The implementation of pulsed heating provides, along with steam blanching, an increase in the temperature level of the product, which allows pouring in jars of syrup of high temperature $\left(97-98^{\circ} \mathrm{C}\right)$, while the traditional technology accounts for a temperature of $80-85^{\circ} \mathrm{C}$.

Implementation of this method provides the temperature level of the product arriving at pasteurization stage of $78-80{ }^{\circ} \mathrm{C}$, unlike the traditional method, ensuring the temperature of the product at 45 $48{ }^{\circ} \mathrm{C}$. After that, the jars are filled with syrup with a temperature of $97-98^{\circ} \mathrm{C}$, then the jars are sealed and sent for accelerated sterilization.

The average initial temperature of the product in the jar after sealing according to the proposed method reaches $78-80^{\circ} \mathrm{C}$, as with blanched in water, it stops biochemical processes, suppresses the vitality of microorganisms, as well as ensures the permeability of protoplasm cells and removal of air from the tissues of fruits.

In addition, an increase in the initial temperature of the product, which happens when using the proposed method, by more than $35-40{ }^{\circ} \mathrm{C}$ compared to the traditional method, will contribute to both reducing the temperature difference between the most and least heated points of the product during sterilization, and to reducing thermal sterilization regimes by more than $35-$ $40 \%$, compared to traditional technology $[14,15,16,17]$. To implement this method, the design of the device for pulse-steam blanching of the fruit in glass jars has been developed [18], see figure 1.

Here's how the device works. Glass jars 4, after filled with the prepared fruit, are fed into chamber with transporter 3, consisting of transporting tape, lead 2 and driven 16 drums, which intermittently moves at intervals of $10 \mathrm{~s}$, where, when the transported stops, they appear under the nozzles serving steam. Steam from pipe 10 and steam distributor 17 through nozzles 5 is fed into jars of 
fruit. Then, after 10 seconds of steam supply to the jars, jars move, ending up under the following nozzles, and the process repeats until they go through the entire processing chamber, consistently being under all nozzles at intervals of 10 seconds. Fruits during processing for 100-160 seconds (depending on the volume of jars) due to steam condensation are heated to $70-75^{\circ} \mathrm{C}$. In the device, in order to prevent thermal cracking of the jars during the steam supply into them, the outer surface of the cans is blown at with heated air with temperature of $110-120{ }^{\circ} \mathrm{C}$ and speed of $3-5 \mathrm{~m} / \mathrm{s}$ supplied through the pipe 12 , and the exhaust air is fed back through the pipe 15 to the heater. The heat treatment chamber is surrounded by a casing 11 .

Taking into account the increased temperature level of the product in the jars, by heating the fruit in the jars with saturated steam and pouring high-temperature (97$98^{\circ} \mathrm{C}$ ) syrup, it is possible to pasteurize the product using accelerated modes.

Figure 1 shows the heating curves and expiration rate of microorganisms during pasteurization $[16,17,18]$ of pear compote for dietary nutrition in jars of CKO 1-82350 type with pulsed steam blanching of fruits in jars and pasteurization using a new accelerated regime: $\frac{3-8-18}{95-100-40} \cdot 88 \mathrm{kPa}$.

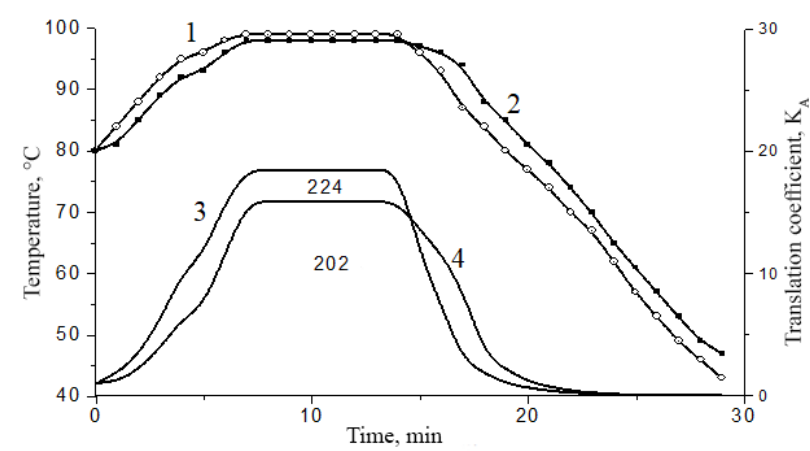

Fig. 2. Charts of temperature changes $(1,2)$ and microorganism expiration rate $(3,4)$ in the wall $(1,3)$ and central $(2,4)$ areas of the glass jar during pasteurization of pear compote for dietary nutrition using pulse-steam blanched fruit in jars.

As we can see from the figure, the mode provides industrial sterility level of the finished product, as the values of sterilizing effects meet the required values for compote, amounting to 150-200 conditional minutes $[15,19]$, and compared to the traditional method, the duration of heat treatment is reduced by 31 minutes, which naturally contributes to significant improvement of the product quality.

In addition, by partially removing air from the fruits and jars before sealing, it provides the possibility of reducing the amount of anti-pressure in autoclaves to the value of $88 \mathrm{kPa}$.

\section{Discussion}

The method also provides substantial heat savings by reducing heat losses, as the method, due to the high temperature of the fruit, provides the ability to pour the syrup into jars at a higher temperature of $98^{\circ} \mathrm{C}$, which during production of one tube of canned goods amounts to about $15,000 \mathrm{~kJ}$.

The thermal energy savings are also provided by replacing the traditional blanching process with pulsed steam blanching, which adds more than $35,000 \mathrm{~kJ}$.

Based on the results, the advanced technology of pear compote production with the use of pulse-steam blanched fruits with saturated water vapor in glass jars and accelerated pasteurization modes (Figure 2) has been proposed.

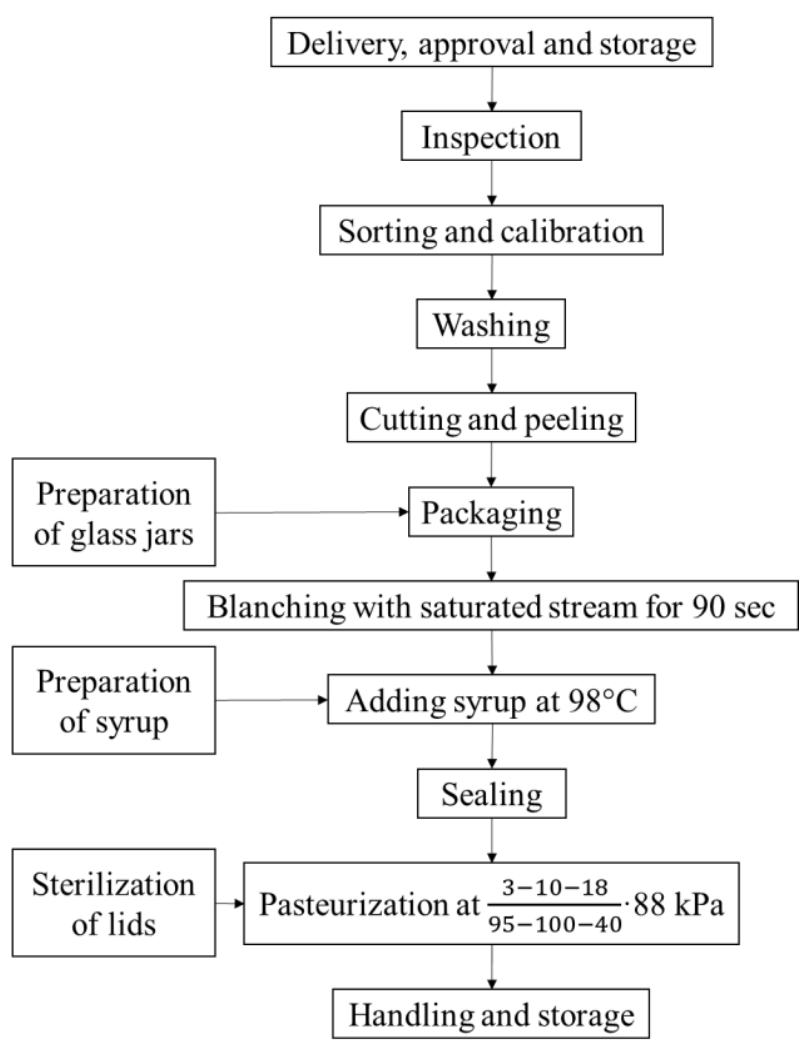

Fig. 3. Advanced technology for the production of pear compote for dietary nutrition using pulse-steam blanched fruits and accelerated pasteurization modes.

The study of quality indicators of compote confirms its high quality.

\section{Conclusion}

The results of the research confirm the effectiveness of the proposed method of pulse-steam blanching of fruits directly in glass jars, as providing high-quality products. This technology can be offered for introduction in enterprises producing canned goods for application in the production of canned compotes for dietary nutrition, instead of traditional technology.

The studies were supported by a grant from the Head of the Republic of Dagestan 2019.

\section{References}

[1] M.E. Akhmedov, A.F. Demirova, G.I. Kasyanova, M. Darbisheva, T.N. Daudova, L.A. Daudova, Use of moderate regimes of heat 
sterilization in the production of cherry compote, Allerton Press, Inc., Russian Agricultural Sciences, 42, 1, 113-116 (2016). ISSN: 10683674.

[2] G. Kasyanov, T. Davydenko, High-tech processing of secondary resources of winemaking, Food Science and Technology, 11, 1 (2017).

[3] T. Orikasa, S. Koide, H. Sugawara, T. Watanabe, M. Okada, U. Matsushima, K. Kato, Y. Muramatsu, M. Thammawong, N. Nakamura, T. Shiina, A. Tagawa, Drying kinetics and quality of tomato fruits dehydrated by a vacuum microwave method, ActaHorticulturae, 1120, 375-380 (2016).

[4] E.E. Abano, H. Ma, W. Qu, Influence of combined microwave-vacuum drying on drying kinetics and the quality of dried tomato slices Journal of Food quality, 35, 3, 159-168 (2012).

[5] K. Sakibaev, L. Pylypenko, T. Nikitchina, G. Kasyanov, Improvement of technology and assessment of consumer properties of breakfast cereals, Food Science and Technology, 13, 2 (2019).

[6] A.F. Demirova, M.E. Akhmedov, M.M. Alibekova, T.N. Daudova, M.M. Omarov, S.A. Abdulkhalikov, Improving the production of canned apple compote using secondary resources and intensive sterilization regimes, Russian Agricultural Science, 4, 61-64 (2018).

[7] V. Derevenko, G. Kasyanov, L. Pylypenko, Studying the properties of grape pomace as an object of drying, FoodScience and Technology, 12, 2 (2018).

[8] M. Aider, E. Olkhovatov, L. Pylypenko, T. Nikitchina, G. Kasyanov, Secondary plant resources as promising non-traditional sources of pectin, Food Science and Technology, 12, 4 (2018) [Electronic resource]. Available at: https://journals.onaft.edu.ua/index.php/foodtech/a rticle/view/1198" \t"_blank.

[9] R.S. Omarov, S.N. Shlykov, A.A. Nesterenko, A. Kazakova, Complex use of raw materials of animal and vegetable origin for the production of new types of desserts, Indo American journal of pharmaceutical sciences, 06, 04, 7072-7077 (2019).

[10] A. Nesterenko, V. Goushchin, A. Koshchaev, M. Rebezov, M. Khayrullin, Use of the electromagnetic field of low frequencies in the production of sausages, International Journal of Engineering and Advanced Technology, IJEAT, 9, 2, 860-869 (2019).

[11] Collection of technological instructions for the production of canned goods, Food Industry VNIIKOP, Moscow, 2, 355 (1977).

[12] B.L. Flaumenbaum, S.S. Tanchev, M.A. Grishin, Basics of Food Sterilization, Agropromizdat, Moscow, 264 (1986).
[13] V.P. Babarin, Canned sterilization, GIORD, St. Petersburg, 312 (2006).

[14] M.E. Akhmedov, Intensification of thermal sterilization technology of canned "Compote of apples" with preheating of fruit in the EMF microwave, Bulletin of universities, Food technology, 1, 15-16 (2008).

[15] G.I. Kasyanov, A.F. Demirova, M.E. Akhmedov, Innovative technology of sterilization of fruit and vegetable raw materials, Reports of the Russian Academy of Agricultural Sciences, 6, 57-59 (2014).

[16] G.I. Kasyanov, Prospects for processing food raw materials by low frequency electromagnetic field, Bulletin of universities, Food Technology, 1 (2014).

[17] O.R. Panina, G.I. Kasyanov, S.V. Rohman, Development of microwave-sterilization regimes of lunch cans, Bulletin of universities, Food Technology, 1 (2014).

[18] M.E. Akhmedov, N.G. Zagirov, A.F. Demirova, M.M. Akhmedov, R.A. Rachmanova, Device for heating fruits and vegetables in glass jars, Patent of Russian Federation no. 2666371 dated 07.09.2018.

[19] Guide to developing sterilization and pasteurization modes for canned products, established by GNU VNIIKOP (2011). 